\title{
Influência da sinvastatina na reparação óssea de mandíbulas de ratas
}

KARINE TENÓRIO LANDIM* ; JULIANA CAMPOS JUNQUEIRA***; ROSILENE FERNANDES DA ROCHA***

\section{Resumo}

O objetivo deste trabalho foi avaliar os efeitos da sinvastatina na reparação óssea guiada em mandíbulas de ratas através da densitometria óptica e análise histológica. Foram utilizadas 35 ratas, nas quais foi confeccionado um defeito ósseo bicortical no ângulo da mandíbula, que foi recoberto por barreira de politetrafluoretileno nas faces vestibular e lingual. Após a cirurgia, os animais foram divididos em 4 grupos tratados com $20 \mathrm{mg} / \mathrm{kg} /$ dia de sinvastatina, via oral, durante 15 ou 30 dias e 3 grupos controle. Os animais foram sacrificados 15,30 ou 60 dias após a cirurgia, sendo a mandíbula removida para realização de densitometria óptica e análise histológica. Todos os espécimes foram submetidos à análise de variância (ANOVA) e teste de Tukey. Os resultados demonstraram que não houve diferença entre os grupos tratado e controle e que a média de neoformação óssea foi maior nos grupos sacrificados em 60 dias, seguidas pelas médias dos grupos de 30 e 15 dias. Conclui-se que a sinvastatina não teve efeito sobre o processo de reparo do tecido ósseo e que a quantidade de neoformação óssea aumentou conforme o tempo de observação.

\section{UNITERMOS}

Sinvastatina; regeneração óssea; mandíbula; rata

LANDIM, K.T.; JUNQUEIRA, J.C., ROCHA, R.F. Influence of the sinvastatin on bone regeneration of mandibles of rats. PGR - Pós-Grad Rev Fac Odontol São José dos Campos, v.5, n.1, jan./abr. 2002.

\section{Abstract}

The purpose of this study was to avaluate the effects of the simvastatin on guided bone regeneration of mandibules of rats. 35 female rats were utilized, a bone defect was created in the mandible, which was covered by a polytetrafluoroethylene barrier on lingual and vestibular surfaces. After surgery the rats were divided in 4 treated groups with $20 \mathrm{mg} / \mathrm{K} /$ day of simvastatin orally 15 or 30 days. The rats were sacrificed 15, 30 and 60 days after the surgery and the mandibles were extracted to densitometric and histological analysis. All specimens were submitted to analysis of variance (ANOVA) and to Tukey's method. The results showed no statistical difference was observed between the treated and control group and the average of new bone formation was bigger in the group sacrificed 60 days after surgery followed for the groups of 30 and 15 days. It can be concluded that the simvastatin didn't have effect on guided bone regeneration and that quantity of bone regeneration increased with the observation time.

\section{UNITERMS}

Simvastatin; statin; bone regeneration; mandibles, rats

\section{INTRODUÇÃo}

O estudo das deficiências ósseas é de suma importância para a Odontologia na medida em que afeta várias especialidades (Pecora et al. ${ }^{20}, 1997$ ), como a periodontia, implantodontia, cirurgia e outras, além de que o interesse pelo conhecimento do metabolismo ósseo tem aumentado nos últimos anos, principalmente em função do avanço dos implantes ósseo integrados como tratamento preferido pelos pacientes no caso de perda do elemento dentário.

Normalmente, durante o processo de reparação de um defeito ósseo, o periósteo e o endósteo proliferam formando um tecido rico em células osteogênicas, o qual irá envolver o defeito (Junqueira \& Carneiro $\left.^{12}, 1999\right)$. Porém, essa reparação é incompleta devido ao rápido crescimento de tecido conjuntivo dentro do tecido ósseo (Dahlin et al. ${ }^{10}$, 1994), para solucionar este problema surgiu a técnica de regeneração óssea guiada, a qual implica na utilização de barreiras mecânicas para isolar um

\footnotetext{
* Aluna da graduação - Faculdade de Odontologia de São José dos Campos - UNESP - 12245-000 São José dos Campos - SP.

** Aluna do Programa de Pós-Graduação em Odontologia - Área de Biociências e Diagnóstico Bucal - Faculdade de Odontologia de São José dos Campos - UNESP - 12245-000 São José dos Campos - SP.

*** Departamento de Biociências e Diagnóstico Bucal - Faculdade de Odontologia de São José dos Campos - UNESP - 12245-000 São José dos Campos - SP.
} 
sítio anatômico, com a finalidade de selecionar um tecido e excluir outros, direcionando a regeneração e impedindo a participação do tecido conjuntivo nesse processo (Novaes \& Batista ${ }^{17}, 1999$ ).

A regeneração óssea é regulada por hormônios, citocinas e fatores de crescimento, como a proteína óssea morfogenética (BMP) (Bostrom ${ }^{4}, 1998$; King et al. ${ }^{14}$, 1997).

Existem na literatura vários estudos com medicamentos que apresentam ação no tecido ósseo, entre estes a calcitonina (Arnett \& Dempster $\left.{ }^{1}, 1987\right)$, os bifosfonatos (Osterman et al. ${ }^{18}, 1997$ ) e as estatinas. Estas agem inibindo a 3 - hidroxi 3 metilglutaril coenzima A redutase (HMG CoA redutase) de maneira competitiva, específica e reversível (Rang \& Dale $\left.{ }^{21}, 1993\right)$, sendo eficazes na redução do nível de colesterol plasmático e amplamente utilizadas no tratamento de hipercolesterolemia. Entre elas temos a mevastatina, lovastatina, sinvastatina, pravastatina, fluvastatina, atorvastatina e cerivastatina (Witztum ${ }^{27}$, 1996; Page et al. ${ }^{19}$, 1999; Bellosta et al. $\left.{ }^{2}, 2000\right)$.

Mundy et al. ${ }^{16}$ (1999) verificaram que a lovastatina e a sinvastatina aumentam o volume do osso trabecular quando administradas oralmente em ratos, pois estimulam a atividade osteoblástica através do aumento da expressão da proteína morfogenética óssea-2 (BMP-2).

Relatos recentes mostram que as estatinas podem ter efeitos benéficos no tratamento de desordens na remodelação óssea incluindo osteoporose e fraturas ósseas (Wang et al..$^{25}$, 1995; Wang et al. ${ }^{26}$, 2000; Sugiyama et al.22, 2000; Chan et al. ${ }^{7}, 2000$ ), por resultarem no aumento da densidade mineral do osso (Chung et al. ${ }^{8}, 2000$ ).

Estes medicamentos têm sido amplamente estudados, pois surgem como uma alternativa de tratamento ao enxerto autógeno, em casos de grandes perdas ósseas resultantes de cistos, infecções, tumores e traumas, além da recuperação de cirurgias reconstrutivas periodontais, com a finalidade de corrigir os defeitos ósseos decorrentes da inflamação periodontal e criar a possibilidade de reparar os tecidos reabsorvidos.

Neste trabalho avaliamos histológica e densitometricamente a ação da sinvastatina no processo de reparação óssea em mandíbulas de ratas.

\section{Material e Método}

Neste trabalho foram utilizadas trinta e cinco ratas (Rattus norvegicus, var. albinus, Wistar) com noventa dias de idade e peso de $250 \mathrm{~g}$. Os animais foram anestesiados com solução de Rompun (Bayer do Brasil) e Francotar (Virbac do Brasil) na proporção de $1: 0,5 \mathrm{~mL}$ na dose de $0,1 \mathrm{~mL} / 100 \mathrm{~g}$, via intramuscular, para confecção de defeito ósseo bicortical no ângulo da mandíbula. Após a anestesia e exposição da superfície óssea, o defeito foi confeccionado com brocas de 2,5 e $3,7 \mathrm{~mm}$ de diâmetro, utilizando-se um motor elétrico de baixa rotação na velocidade de $1500 \mathrm{rpm}$ e irrigação abundante de solução de $\mathrm{NaCl}$ a $0,9 \%$. A seguir a lesão foi recoberta por numa barreira de politetrafluoretileno puro, não biológica e não absorvível, por vestibular e lingual, excedendo $2 \mathrm{~mm}$ das margens do defeito, sendo a camada muscular e a pele suturadas.

Após a cirurgia os animais foram divididos em dois grupos experimentais:

- grupo I (controle) - composto por quinze animais que foram sacrificados em quinze (1C), trinta (2C) e sessenta dias (3C) após a lesão óssea;

- grupo II (tratado) - composto por vinte ratas tratadas com sinvastatina via oral na dose de $20 \mathrm{mg} / \mathrm{kg} / \mathrm{dia}$, por 15 ou trinta dias. Os animais que receberam sinvastatina por 15 dias foram sacrificados em quinze (1T) e trinta dias (2T) após a cirurgia e os tratados por trinta dias, sacrificados em trinta (3T) e sessenta dias (4T).

Para o sacrifício, as ratas foram anestesiadas, decapitadas e tiveram suas hemi-mandíbulas direitas removidas e fixadas em formol a $10 \%$.

Para análise da densidade óptica do defeito ósseo, foram realizadas radiografias com filme oclusal (Kodak Ektaspeed Plus EO-41P, size 4), sendo que, sobre cada filme, foram colocadas duas hemimandíbulas com a face vestibular voltada para o RX, uma do grupo tratado e uma do controle de mesmo período de sacrifício. E no centro da película, paralelamente e entre os espécimes, colocouse uma escala padrão de alumínio (step wedge).

As mandíbulas foram submetidas à análise radiográfica com emprego de aparelho de RX Odontoló- 
gico (General Eletric - GE 1000 - modelo 11A5A7), utilizando-se $65 \mathrm{KV}, 10 \mathrm{~mA}$ e 0,25 segundos de exposição, distância foco-objeto de $40 \mathrm{~cm}$ e revelação em processadora automática (Gendex GXP).

Para a medição das densidades ópticas das radiografias foi empregado fotodensitometro (M.R.A.), sendo as leituras realizadas no centro dos defeitos ósseos e nos degraus da escala de alumínio de cada radiografia. A densidade óptica de cada uma dessas estruturas foi medida dez vezes, sendo cinco realizadas logo após o processamento das radiografias e as outras após um período de quinze dias, obtendo-se uma média das mesmas.

Os valores da densitometria óptica foram transformados em equivalente de alumínio através de um modelo de regressão linear (Kolbeck et al. ${ }^{15}$, 1999) e submetidos à análise estatística de variância (ANOVA) com nível de significância de 5\% (Vieira $\left.{ }^{23}, 1986\right)$.

Para análise histológica as hemi-mandíbulas direitas foram descalcificadas em solução aquosa de ácido fosfórico a 20\%. A seguir, as mesmas foram hemisseccionadas na região do defeito ósseo no sentido ântero-posterior e de cada fragmento foram obtidos cortes seriados corados pela hematoxilina-eosina. As lâminas foram analisadas quanto a neoformação óssea, presença e remodelação de trabéculas ósseas e existência de tecido de granulação.

\section{Resultados}

\section{Análise da densidade óptica:}

Os resultados da densidade óptica em espessura de alumínio dos grupos controle e tratado apresentaram-se semelhantes (Tabela 1).

Entretanto houve diferença estatisticamente significante entre os grupos sacrificados em quinze e trinta e os de sessenta dias (Tabela 2).

Quanto ao tempo de tratamento verificou-se que existem diferenças estatísticas entre os grupos $2 \mathrm{~T}$ e 3T e entre 3T e 4T (Tabela 3).

Tabela 1 - Médias e desvio padrão das densidades ópticas em espessura de alumínio dos grupos experimentais

\begin{tabular}{cc}
\hline & Grupos \\
\hline Controle & Tratado \\
$0.35 \pm 0.08$ & $0.39 \pm 0.09$ \\
\hline
\end{tabular}

Tabela 2 - Médias e desvio padrão das densidades ópticas em equivalentes de alumínio dos períodos de observação

\begin{tabular}{ccc}
\hline & Tempo de sacrifício & \\
\hline 15 dias & 30 dias & 60 dias \\
$0.32 \pm 0.07$ & $0.36 \pm 0.10$ & $0.44 \pm 0.05$ \\
\hline
\end{tabular}

Tabela 3 - Médias e desvio padrão das densidades ópticas em espessura de alumínio das condições de tratamento

\begin{tabular}{cccc}
\hline T:15 dias S:15dias & T:30 dias S:30 dias & T:30 dias $S: 30$ dias & T:60 dias S:60 dias \\
\hline$(1 \mathrm{~T})$ & $(2 \mathrm{~T})$ & $(3 \mathrm{~T})$ & $(4 \mathrm{~T})$ \\
$0.36 \pm 0.07$ & $0.44 \pm 0.13$ & $0.31 \pm 0.03$ & $0.44 \pm 0.03$ \\
\hline
\end{tabular}

T: tempo de tratamento

S: tempo de sacrifício 


\section{Análise histológica:}

A reparação óssea dos grupos controle e tratado foram semelhantes.

No período de quinze dias de sacrifício, o defeito ósseo foi preenchido por tecido de granulação bem celularizado e vascularizado. Nas margens da lesão observou-se tecido osteogênico, algumas trabéculas ósseas imaturas contornadas por osteoblastos, grande número de osteócitos volumosos inclusos e alguns osteoclastos. Estas trabéculas ósseas delimitavam espaços medulares amplos e preenchidos por tecido conjuntivo frouxo (Figura 1). Observou-se também tecido ósseo neoformado a partir do periósteo adjacente à lesão óssea que se continuava com as trabéculas formadas dentro do defeito (Figura 2).

No período de trinta dias de sacrifício, a área central do defeito ósseo foi preenchida por tecido

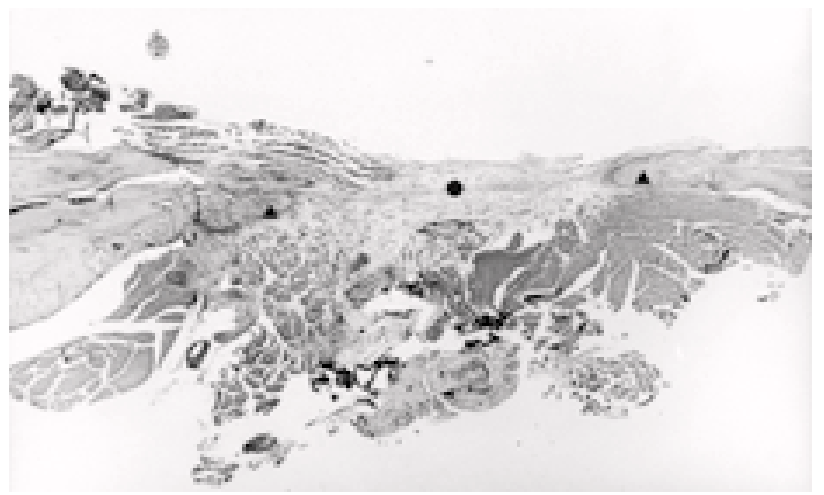

FIGURA 1 - Período de quinze dias, grupo controle (1C): defeito ósseo preenchido por tecido de granulação $(\bullet)$ e neoformação óssea junto às margens $(\boldsymbol{\Delta})$. Aumento original $25 \mathrm{X}$.

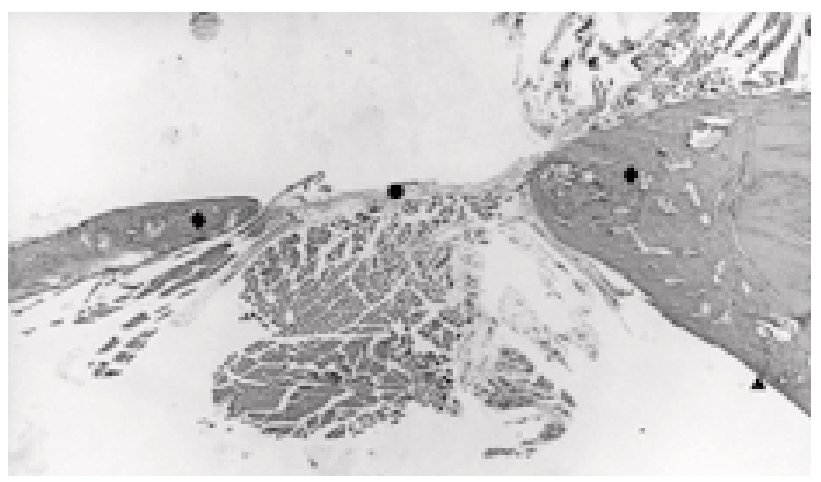

FIGURA 3 - Período de trinta dias, grupo tratado por trinta dias (3T): lesão apresentando tecido de granulação na região central $(\bullet)$ e trabéculas ósseas nas margens $(\bullet)$, originárias de neoformação subperiosteal $(\boldsymbol{\Delta})$. Aumento original 25X. de granulação e as margens por trabéculas ósseas neoformadas mais maduras, que se estendiam para o centro do defeito. Nessas trabéculas notou-se a presença de numerosos osteócitos menores, que por vezes se dispunham em padrão lamelar, e espaços medulares, de tamanhos variados, contendo tecido conjuntivo frouxo ou tecido medular hematopoiético (Figura 3 e 4).

No período de sessenta dias de sacrifício, a loja cirúrgica, encontrou-se preenchida por tecido ósseo neoformado, exceto na área central, onde ainda permanecia o tecido conjuntivo(Figura 5). As trabéculas ósseas apresentavam-se maduras com osteócitos pequenos dispostos de forma lamelar. Observaram-se ainda linhas de aposição e pequenos espaços medulares com tecido hematopoiético (Figura 6). Na extremidade posterior do defeito não foi possível determinar o limite entre o osso antigo e neoformado .

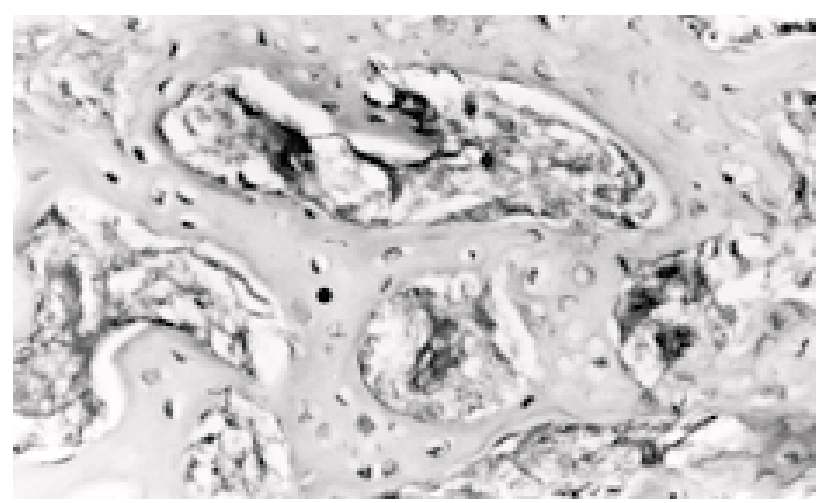

FIGURA 2 - Período de quinze dias, grupo tratado (1T): trabéculas ósseas imaturas $(\bullet)$ delimitando grandes espaços medulares preenchidos por tecido conjuntivo $(\diamond)$. Aumento original $400 \mathrm{X}$.

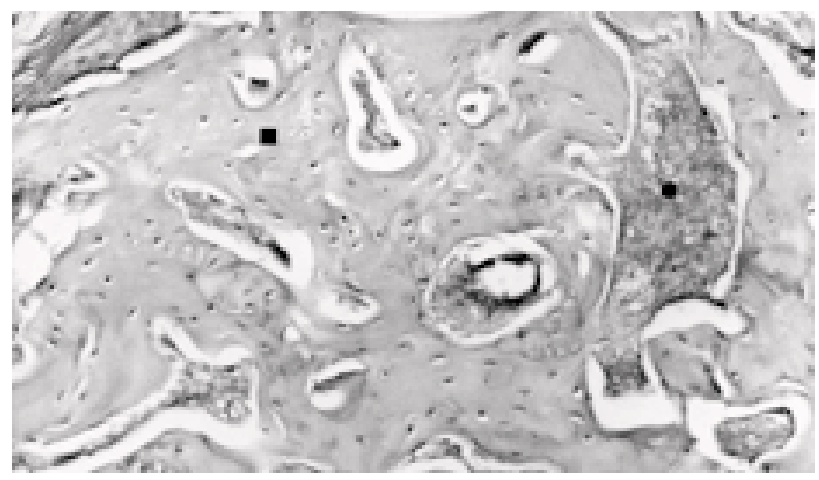

FIGURA 4 - Período de trinta dias, grupo tratado por trinta dias (3T): trabéculas ósseas neoformadas espessas (ם), contornando vários espaços medulares preenchidos por tecido conjuntivo (-). Aumento original 200X. 


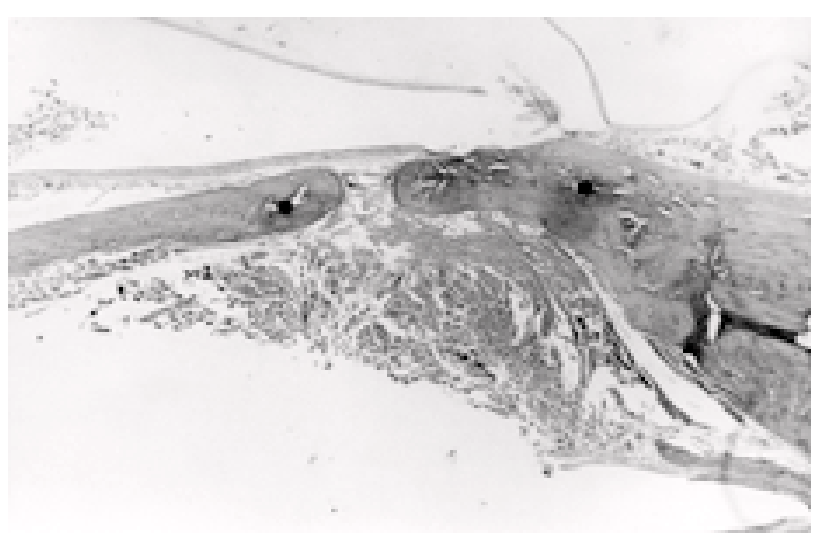

FIGURA 5 - Período de sessenta dias, grupo controle (3C): tecido ósseo neoformado $(\bullet)$ que se estende da margem do defeito $(\boldsymbol{\Delta})$ em direção a porção central do mesmo. Aumento original $25 \mathrm{X}$.

\section{Dıscussão}

Atualmente, as estatinas têm sido utilizadas no tratamento da hipercolesterolemia, por inibirem competitivamente a atividade da HMG Co-A redutase nas células hepáticas (Witztun et al. ${ }^{27}$, 1996).

Mundy et al. ${ }^{16}$ (1999) foram os primeiros a descreverem a capacidade das estatinas em aumentar a expressão da BMP em cultura de células ósseas humanas e de camundongos, estimulando formação óssea in vitro e in vivo.

Estudos constataram que, além da diminuição do colesterol sérico, esses medicamentos apresentam efeitos benéficos no tratamento da osteoporose e diminuição no risco de fratura óssea (Sugiyama et al. ${ }^{22}$, 2000; Wang et al. ${ }^{25}$, 1995; Mundy et al. ${ }^{16}, 1999$ ), o que nos incentivou a desenvolver este trabalho com o objetivo de observar os efeitos da sinvastatina na reparação óssea em mandíbulas de ratas.

A densitometria óptica é um método de avaliação da mineralização da matriz orgânica (Victor et al. ${ }^{24}$, 1977; Carvalho et al. ${ }^{5}, 1978$ ) através da medição do negrume do filme por um fotodensitômetro, que compara a intensidade da luz que entra em uma determinada área em um lado do filme revelado com a intensidade daquela luz quando ele emerge pelo outro lado (Eastman Kodak Company $\left.{ }^{11}, 1980\right)$. Kolbeck ${ }^{15}$ (1999) utilizou radiografia digital para monitorar e quantificar a neoformação óssea e comprovou sensibilidade deste

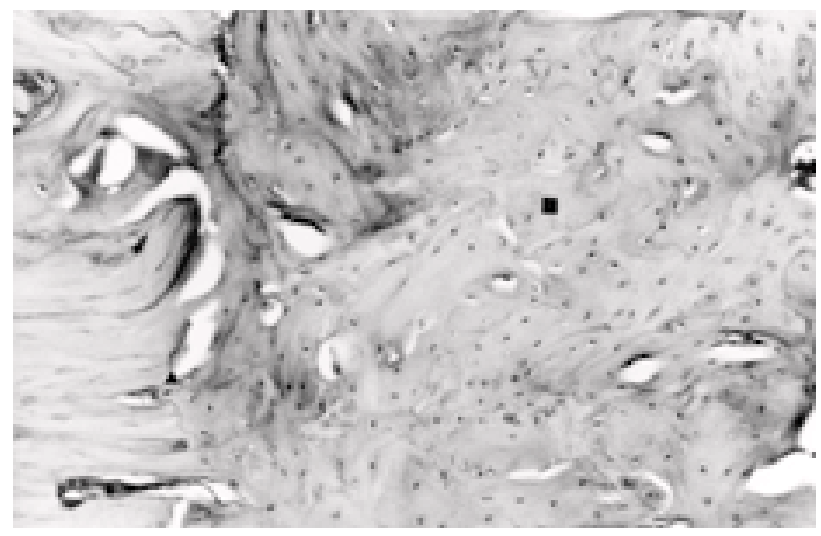

FIGURA 6 - Período de sessenta dias, grupo controle (3C): tecido ósseo neoformado maduro (ם) a partir da margem do defeito (A). Aumento original 400X.

método na avaliação do processo de reparação, pois houve aumento significativo na densidade óptica para pequenos intervalos de tempo.

Estudos verificaram semelhanças entre resultados da análise histológica e densitométrica, comprovando a eficácia da densitometria (Carvalho et al. ${ }^{6}, 1980$; Bodner et al. ${ }^{3}, 1993$ ) na avaliação da reparação óssea.

$\mathrm{Na}$ análise histológica dos grupos estudados no presente trabalho, verificou-se que a reparação óssea ocorreu de forma centrípeta e a partir do periósteo, confirmando que o periósteo tem grande potencial osteogênico, sendo por isso fundamental para o processo de reparação (Katburian \& Arana $\left.^{13}, 1999\right)$.

Dahlin et al. ${ }^{9}$ (1988) constataram que defeitos mandibulares de ratos, revestidos por uma barreira de politetrafluoretileno, apresentaram completa cicatrização após 6 semanas da cirurgia. Provavelmente, a reparação óssea em nosso trabalho tenha sido mais lenta pelo fato da barreira ter sido apenas posicionada sobre o defeito, enquanto que Dahlin et al. ${ }^{9}$ (1988) fixaram-na através de uma sutura trans-óssea, sendo que a falta de fixação pode ter favorecido a entrada de tecido conjuntivo interferindo no processo de reparação.

Foram encontrados osteoclastos nos três períodos de observação, principalmente nos grupos de quinze dias, sendo também notadas linhas de reabsorção nos tempos de trinta e sessenta dias. Esses dados indicam que durante o processo de repara- 
ção óssea ocorre remodelação do osso primário, formando um tecido mais maduro, com osteócitos menores e dispostos em padrão lamelar (Junqueira $\&$ Carneiro $\left.^{12}, 1999\right)$.

Em nosso trabalho verificamos que a sinvastatina, administrada oralmente, não atua na reparação de defeito ósseo em mandíbulas de ratas. No entanto, Mundy et al. ${ }^{16}$ (1999) observaram que a administração de lovastatina sobre a calvária de camundongos promoveu formação óssea e que ratas normais e ovarectomizadas tratadas com sinvastatina apresentaram aumento no volume de osso trabecular e redução no número de osteoclastos.

Wang et al. ${ }^{26}$ (2000) e Chan et al. ${ }^{7}$ (2000) analisando históricos médicos de vários pacientes com

\section{REFERÊNCIAS BIBLIOGRÁFICAS}

1. ARNETT, T. R.; DEMPSTER, D. W. A comparative study of disaggregated chick and rat osteoclasts in vitro: effects of cacitonin and prostaglandins. Endocrinol, v.120, n.2, p.602-8, 1987.

2. BELlOSTA, S. et al. Non-lipid-related effects of statins. Ann Med, v.32, n.3, p.164-76, Apr. 2000.

3. BODNER, L. et al. Extraction site healing in rats. Oral Surg Oral Med Oral Pathol Oral Radiol Endod, v.75, n.3, p.367-72, Mar.1993.

4. BOSTROM, M. P. G. Expression of bone morphogenetic proteins in fracture healing. Clin Orthop, v.355, p.116-23, Oct. 1998.

5. CARVAlHO, A. et al. Penetrômetro estojado para determinações densitométricas em radiologia. Ars Cvr Odont, v. 2, p. 28-31, 1978.

6. CARVAlHO, A. et al. Mineralização no processo de reparo em feridas de extração dentária em ratos: contribuição ao estudo densitométrico. Ars Cvrandi Odontol, v.7, n.7, p.30412, Out.1980.

7. CHAN, K. A. et al. Inhibitors of hydroxymethylglutaryl-coenzime A reductase and risk of fracture among older women. Lancet, v.355, n.9222, p.2185-8, Jun. 2000.

8. CHUNG, Y. S. et al. HMG-CoA reductase inhibitors increase BMD in type 2 diabetes mellitus patients. J Clin Endocrinol Metab, v. 85, n. 3, p. 1137-42, 2000

9. DAHLIN, C. et al. Healing of bone defects by guided tissue regeneration. Plast Reconstr Surg, v.81, n.5, p.672-6, May 1988.

10. DAHLIN, C. et al. Restoration of mandibular nonunion bone defects. Int J Oral Maxillofac Surg, v.23, n. 4, p.237-42, 1994.

11. EASTMAN KODAK COMPANY. Resposta do filme. In: Fundamentos de Radiografia. 1980. Cap.5, p.45-56.

12.JUNQUEIRA, L. C.; CARNEIRO, J. Tecido ósseo. In: Histologia básica. 9.ed. Rio de Janeiro: Guanabara-Koogan, 1999. cap. 8, p.111-28.

13. KATCHBURIAN, E.; ARANA, V. Tecido ósseo. In: _____. Histologia e embriologia oral.. São Paulo : Panamericana, 1999. cap. 3, p.40-75.

14. KING, G. N. et al. Recombinant human bone morphogenetic protein-2 promoters wound healing in rat periodontal fenestration defects. J Dent Res, v.76, n.8, p.1460-70, Aug. 1997. mais de 60 anos de idade constataram que as estatinas conferem proteção contra fratura por osteoporose. Portanto, a sinvastatina parece não ter efeito sobre o processo de reparo ósseo, mas apresenta eficácia no tratamento da osteoporose.

\section{Conclusões}

Através da análise dos resultados concluiu-se que:

- A sinvastatina não teve efeito sobre o processo de reparação óssea;

- A quantidade de neoformação óssea foi maior nos períodos de sessenta dias, seguidos pelos tempos de trinta e quinze dias de sacrifício.

15. KOLBECK, S. et al. Digital radiography. A predictor of regenerate bone stiffness in distraction osteogenesis. Clin Orthop, v. 366, p. 221-8, Sept.1999.

16. MUNDY, G. et al. Stimulation of bone formation in vitro and in rodents by statins. Science, v.286, p.1946-51, 1999.

17.NOVAES, JUNIOR.; A. BATISTA. JUNIOR,; BATISTA, E. L. B. Técnicas regenerativas em periodontia. In: TUNES, U. R., RAPP, G. E. Atualização em periodontia e implantodontia. São Paulo : Artes Médicas, 1999

18. OSTERMAN, T. et al. Distribution of clodronate in the bone of adults rats and its effects on trabecular and cortical bone. J Pharm Exp Ther, v.280, n.2, p.1051-6, 1997.

19.PAGE, C. P.; et al. As drogas e os sistemas endócrino e metabólico. In: Farmacologia integrada. Trad. I.C. Gubert. São Paulo: Manole, 1999. cap.12, p.253-86.

20.PECORA, G. et al. Bone regeneration with a calcium sulfate barrier. Oral Surg Oral Med Oral Pathol Oral Radiol Endod, v.84, n.4, p.424-9, Oct. 1997.

21. RANG, H.P., DALE, M. M. Farmacologia. 2 ed. Rio de Janeiro : Guanabara Koogan, 1993. Cap.15, p.230-4.

22. SUGIYAMA, M. et al. Compactin and sinvastatin, but not pravastatin, induce bone morphogenetic protein - 2 in human osteosarcoma cells. Biochem Biophys Res Commun, v. 271, n.3, p. 688-92, 2000.

23. VIEIRA, S. Introdução à bioestatística. 4.ed. Rio de Janeiro : Campus, 1986. 294p.

24. VICTOR, J. O. et al. Implante de gesso Paris em alvéolos dentais de ratos. Contribuição ao estudo radiográfico. Rev Assoc Paul Cirurg Dent, v.31, n.6, p.382-6, 1977.

25.WANG, G. et al. Lipid clearing agents in steroid-induced osteoporosis. J Formos Med Assoc, v. 94, n. 10, p. 589-92, 1995.

26. WANG, P. S. et al. HMG-CoA reductase inhibitors and the risk of hip fractures in elderly patients. J Formos Med Assoc, v.283, n. 24, p. 3211-16, June. 2000.

27. WITZTUM, J. L. Fármacos usados no tratamento das hiperlipoproteinemias. In: GOODMAN, L. S., GILMAN, A. As bases farmacológicas da terapêutica. Trad. J.G.Hardvan; L.E.Limbird. 9.ed. Rio de Janeiro : McGraw-Hill, 1996. cap.36, p.643-60. 